\title{
Grupos de Estudio Dirigido en la educación veterinaria: una propuesta estudiantil para fortalecer la comunicación de los futuros profesionales
}

\author{
Cadoche L*, Báez ML, Gimenez S, Scaglione MC \\ Facultad de Ciencias Veterinarias, Universidad Nacional del Litoral (FCV-UNL), Argentina. \\ * Correspondencia: Lilián Cadoche. FCV-UNL, Argentina. \\ E-mail: Icadoche@fcv.unl.edu.ar
}

RESUMEN. De la lectura de solicitudes laborales para cualquier empresa, y en particular las relacionadas con la labor del Médico Veterinario, al mismo nivel que los conocimientos científico-técnicos se solicita que éste posea "espíritu proactivo", "capacidad de liderazgo" "competencias para trabajar en equipo", entre otras habilidades sociales importantes. Ya no alcanza con saberes "sabios" ni experiencia "técnica", hoy se necesitan sujetos hábiles para la comunicación, con confianza en sí mismos y en los demás, solidarios, empáticos con su entorno y capaces de integrarse con éxito a equipos de trabajo. En el currículo oficial de la carrera de Medicina Veterinaria de la Universidad Nacional del Litoral, la habilidad de trabajar en equipo no forma parte de los contenidos específicos que el estudiante debe aprender. Los Grupos de Estudios Dirigidos (GED), son grupos de alumnos de distintos niveles de la carrera, que motivados por un tema en común gestionan tareas de profundización en temáticas específicas, investigación y/o extensión para fortalecerse en esa área. Para ellos aprender a trabajar en equipo implica aprender a comunicarse eficazmente, a ser solidario, a comprometerse con el logro de metas comunes, habilidades que no deben descuidarse y que son fundamentales para hablar de un profesional con una formación integral.

SUMMARY. Directed Studies Groups in the veterinary education: a proposal to enhance communication in future professionals. Reading job applications sent to any company and, particularly, those related to the Veterinary profession, it becomes clear that, apart from the required specific technical and scientific expertise, applicants should also have a proactive spirit, leadership abilities and the capacity to work in a team, among other important social skills. Nowadays, it's not enough having "wise" knowledge or "technical" expertise. Subjects should also have the ability to communicate effectively, demonstrate they can rely upon themselves and others, be sympathetic and empathetic and capable of integrating successfully in new work teams. In the official syllabus of the Veterinary Medicine career in Argentina, the ability to work in teams is not part of the specific content that the students have to learn. The Directed Studies Groups (DSG), are groups of students of different levels of the graduate course, that motivated by a common topic embark on tasks to deepen their knowledge on specific subjects, including research and / or extension. For them, learning to work in a team means learning to communicate effectively, to be supportive, to commit to the achievement of common goals, skills that should not be neglected and that are fundamental to speak of a professional with a comprehensive education.

Palabras clave: trabajo de equipo, grupos de estudio dirigido, educación Veterinaria

Key words: team work, directed studies groups, veterinary education

De la lectura de actuales solicitudes laborales para cualquier empresa, y en particular las relacionadas con la labor del Médico Veterinario, al mismo nivel que los conocimientos científico-técnicos se solicita que éste posea "espíritu proactivo", "capacidad de liderazgo" "competencias para trabajar en equipo", entre otras habilidades sociales importantes (Cadoche y Prendes, 2011). Este mundo de la información tan globalizado ha vuelto su mirada al recurso humano y sus habilidades interpersonales (Avendaño y Perrone, 2012). Ya no alcanza con conocimientos conceptuales, ni experiencia "técnica", hoy se necesitan sujetos hábiles para la comunicación, con confianza en sí mismos y en los demás, solidarios, empáticos con su entorno y capaces de integrarse con éxito a equipos de trabajo. En el currículo oficial de la carrera de Medicina Veterinaria de la Universidad Nacional del Litoral (ver el plan en el sitio: http://www.fcv.unl.edu.ar/media/academicas/2012/documentos/ResHCS29807.pdf), la habilidad de trabajar en equipo no forman parte de los contenidos específicos que el alumno debe aprender, y 
aunque muchos docentes se interesan porque sus alumnos adquieran estas destrezas, no son pocos los que llegan al final de su proceso formativo sin las mínimas aptitudes y conductas que les permitan una adecuada interacción y un trabajo complementario, comprometido, coordinado con sus colegas.

Es tan importante el tema de la comunicación que incluso, La Asociación Panamericana de Veterinaria (PANVET) sugiere como materia de grado a la comunicación.

En la Facultad de Ciencias Veterinarias de la Universidad Nacional del Litoral (FCV-UNL), existen Grupos de Estudios Dirigidos, los cuales son grupos de alumnos que motivados por un tema en común gestionan tareas de profundización en temáticas específicas, investigación y/o extensión para fortalecerse en esa área. Actualmente hay diez grupos: 'Crianza artificial de terneros'; 'Capibara'; 'Caprinos'; 'Porcino'; 'Aves'; 'Ovinos'; 'Apícola'; 'Leche'; 'Carne' y 'Equinos'. Cada uno de ellos tiene un profesor responsable y un alumno que preside la organización.

Estos conjuntos de estudiantes, tienen un interés especia que los motorizó para reunirse e iniciar estudios, talleres, debates, pero ninguno de ellos recibió asesoramiento específico para constituirse como EQUIPOS DE TRABAJO

Creemos que hablar sobre la importancia de los roles en el trabajo en equipo, liderazgo, compromiso, confianza, coordinación son competencias que aumentarán la calificación de estos alumnos y mejorarán seguramente sus posibilidades de logros en las relaciones interpersonales (Baker et al., 2005). Aprender a trabajar en equipo implica aprender a comunicarse eficazmente, a ser solidario, a comprometerse con el logro de metas comunes, habilidades que no deben descuidarse y que son fundamentales para hablar de un profesional con una formación integral (Latham y Morris, 2007).

Para el desarrollo de las habilidades de trabajo en equipo se decidió realizar diferentes tareas entre las que se incluyó: describir desde la propia percepción de los integrantes de cada Grupo, sus habilidades sociales para integrar el grupo y las dificultades para que el mismo se constituya en Equipo para iniciar en la Institución el debate acerca de la inclusión de actividades que fortalezcan las competencias sociales de los estudiantes.

Las actividades implicadas en esta tarea de socializar las ventajas del trabajo en equipo implicaron primero la lectura reflexiva de material que aclare el concepto de EQUIPO, y experiencias previas de otros autores sobre esta tarea (Dyer, 1988). Se buscaron y proyectaron en encuentros previamente citados con los grupos mencionados, videos en los que éstos jóvenes pudieron observar distintas formas de trabajar en equipo y formas correctas de comunicación. Al finalizar los mismos, se consultó sobre sus opiniones, las que resultaron alentadoras ya que la mayoría de los participantes $(n=70)$ ponderó muy positivamente la propuesta. A los integrantes de los diferentes grupos se les realizó una encuesta online, para conocer su autopercepción respecto de las habilidades para el trabajo en equipo, las que fueron contestadas por un $70 \%$ de los invitados. Estas encuestas incluyeron 13 consignas algunas abiertas y otras cerradas tales como: para Ud. ¿qué significa comunicarse eficazmente?; ¿Qué cree Ud. que se necesita para comunicarse oralmente de manera eficaz?; ¿Los recursos o elementos que se requieren para la comunicación oral en un grupo de amigos, en un aula de la facultad o en una jornada científica son similares?; ha expuesto oralmente en alguna de las siguientes circunstancias: Seminarios en asignaturas, de estudios dirigidos, exposición en jornadas de divulgación, etc.; empleo la modulación y el volumen de voz para reforzar lo que digo; en una conversación presto atención cuando me hablan; argumento mis ideas en un debate, entre otras.

En los encuentros realizados, las charlas, observación de videos y debates, originaron interesantes diálogos que mostraron el interés generado por la propuesta. De las encuestas mencionadas podemos mencionar algunas respuestas interesantes. A la consigna relacionada con el significado de comunicarse eficazmente algunas de las respuestas fueron:

-Que la información que se desea transmitir sea clara por parte del emisor y que el receptor la entienda.

-Poder transmitir y que se entienda lo que estoy comunicando.

-Que el mensaje llegue en su totalidad al receptor.

-Ser claro y específico.

-Transmitir toda la información disponible y las diferentes actividades.

-Que la persona a la que te estas dirigiendo interprete lo que le estas diciendo.

Como respuesta a qué creen que es comunicarse eficazmente algunas de las contestaciones fueron:

\section{-Ser claro y conciso.}

-Respeto y aceptación de las distintas opiniones.

-Confianza, claridad y buenos conocimientos.

-Amplitud en el vocabulario y fácil expresión.

Cuando se los interrogó respecto de si en un espacio científico se comunican igual que en uno social cotidiano, aproximadamente el $67 \%$ afirma que no, y el restante $33 \%$ afirma que sí.

Ante la pregunta si ha expuesto oralmente en eventos científicos, un alto porcentaje de más del $80 \%$ respondió que sí. 
Consultados respecto de su modulación y tono de voz para reforzar sus palabras, un $30 \%$ aproximadamente afirmó que siempre lo hace y un $70 \%$ dudó de realizarlo adecuadamente.

Frente a la pregunta relacionada con prestar atención a quien les habla, más del $70 \%$ de los encuestados afirma positivamente, y el resto admite no hacerlo.

Cuando se les preguntó si argumentaban sus ideas en un debate, estimativamente un $40 \%$ expresa que si lo hace, mientras un alto porcentaje (más del $50 \%$ ) sostiene que tiene dificultades para esta argumentación.

De los talleres realizados se puso en evidencia el interés de estos jóvenes por mejorar sus competencias para la comunicación y en consecuencia para el trabajo en equipo. Los organizadores observaron participación, motivación y deseos de que encuentros como este se repitan, y/o formen parte de su proceso formativo permanente.

De las encuestas realizadas concluimos que más allá de que hay un alto porcentaje de alumnos que se percibe a si mismo con adecuadas condiciones para la comunicación, también es alto el que expresa tener dificultades relacionadas con la comunicación científica, y el lenguaje relacionado con el diálogo en seminarios, exámenes orales, debates académicos y otros.

En base a los resultados expuestos se considera necesario insistir en la incorporación en la currícula de formación en ciencias veterinarias una disciplina que aborde como eje central la comunicación como lo expresa la Asociación Panamericana de Ciencias Veterinarias (Taylor et al., 2013) para el profesional del 2030 en la que incluye como materia de grado al tema COMUNICACIÓN.

\section{Bibliografía}

Avendaño F, Perrone A. 2012. El aula: un espacio para aprender a decir y a escuchar: estrategias y recursos. Homo sapiens: Argentina.121pp.

Baker DP, Salas E, King H, Battles J, Barach P. 2005. The ALL teamwork framework. En: Murray TS, Clermont $Y$, Binkley $M$. (Eds.) International Adult Literacy Survey. Measuring Adult Literacy and Life Skills: New Frameworks for Assessment. Ministry of Industry, Otawa. Pp. 229 - 272.

Cadoche L, Prendes C. 2011. Competencias sociales requeridas y observadas en alumnos de Medicina Veterinaria: La visión de los docentes. REDVET- Revista Electrónica de Veterinaria 11:3.

Dyer WG. 1988. Formación de equipos. Problemas y alternativas. Addison-Wesley Iberoamericana, Londres. 186pp.

Latham CE, Morris A. 2007. Effects of formal training in communication skills on the ability of veterinary students to communicate with clients. Vet. Rec. 160: 181-186.
Taylor J, Michel H, Anguiano R, Taylor A, Estrada G. 2013. Perfil Profesional del Médico Veterinario en Latinoamérica -Visión al 2030. En: Taylor Preciado J (Ed.). Perfil Profesional del Médico Veterinario en Latinoamérica, visión al 2030. PANVET. Pp. 65-81. 